\title{
Supporting Information for: Learning about precipitation orographic enhancement from snow-course data improves water-balance modeling
}

Francesco Avanzi ${ }^{1}$, Giulia Ercolani ${ }^{1}$, Simone Gabellani ${ }^{1}$, Edoardo Cremonese ${ }^{2}$, Paolo Pogliotti ${ }^{2}$, Gianluca Filippa ${ }^{2}$, Umberto Morra di Cella ${ }^{2,1}$, Sara Ratto ${ }^{3}$, Hervè Stevenin ${ }^{3}$, Marco Cauduro ${ }^{4}$, and Stefano Juglair ${ }^{4}$

${ }^{1}$ CIMA Research Foundation, Via Armando Magliotto 2, 17100 Savona, Italy

${ }^{2}$ Climate Change Unit, Environmental Protection Agency of Aosta Valley, Loc. La Maladière, 48-11020 Saint-Christophe, Italy

${ }^{3}$ Regione Autonoma Valle d'Aosta, Centro funzionale regionale, Via Promis 2/a, 11100 Aosta, Italy

${ }^{4}$ Direzione Operativa Operations, C.V.A. S.p.A., Via Stazione 31, 11024 Châtillon, Italy

Correspondence: Francesco Avanzi (francesco.avanzi@cimafoundation.org) 


\section{S1 Flood-PROOFS: details}

\section{Input-data spatialization}

In addition to precipitation fields obtained using GRISO1 and GRISO2, simulations of Flood-PROOFS required hourly input data of air temperature, relative humidity, wind, and incoming shortwave solar radiation. Interpolation schemes for these

5 four additional weather variables followed well-established procedures in use by CIMA Research Foundation and the AostaValley civil-protection regional authority (Laiolo et al., 2014). Air temperature was distributed using a laspe rate estimated with ground-based air-temperature measurements from the regional monitoring network, followed by an interpolation of residuals using Inverse Distance Weighting (IDW). Relative humidity, wind, and incoming shortwave solar radiation were interpolated using IDW, favored by the comparatively dense coverage of the regional monitoring network.

\section{S3M snow model}

S3M is a one-layer snow model accounting for precipitation-phase partitioning (rainfall vs. snowfall), snowpack accumulation and melt, as well as snow settling (Boni et al., 2010; Terzago et al., 2019). The main state variables of the model are SWE (in $\mathrm{mm}$ ) and bulk-snow density $\left(\rho_{S}\right.$, in $\left.\mathrm{kg} \mathrm{m}^{-3}\right)$, with snow depth derived from those two state variables according to definition: $\mathrm{HS}=\mathrm{SWE} \times \rho_{W} \times \rho_{S}^{-1}$ (see DeWalle and Rango, 2011, $\rho_{W}$ is water density). Precipitation-phase partitioning is solved using the parametrization by Froidurot et al. (2014), which relies on air temperature and relative humidity. Snowmelt is predicted based on a modified temperature-index approach considering observed shortwave radiation, estimated longwave radiation, air temperature, and a parametrization of snow albedo based on snow age (Laramie and Schaake, 1972). Snow settling is function of fresh-snow density and time, with different settling rates for days with or without concurrent snowmelt; fresh-snow density follows Pomeroy and Brun (2001). S3M also simulates glacier-melt runoff, using the same approach used for snowmelt but with an enhanced degree-day factor and a condition that inhibits glacier melt as long as the pixel is covered by seasonal snow. In the operational setup of Flood-PROOFS that we used here, glacier-mass balance and glacier movement were not considered given the relatively short time scale of flood forecasting. All parameters of S3M were set based on previous validations of this model in Aosta Valley.

\section{Continuum hydrologic model}

Continuum is a continuous-time and spatially distributed hydrologic model accounting for both surface and sub-surface water fluxes. The model includes a coupled mass-energy balance at the soil-atmosphere interface and solves for vegetation interception, surface runoff, infiltration, evapotranspiration, interflow, percolation, as well as groundwater flow on a squared computational grid (Silvestro et al., 2013). Infiltration and subsurface flow are modeled using a modified Horton approach. The energy balance is solved using a "force-restore equation", with an explicit computation of land-surface temperature. Routing of surface runoff is computed distinguishing between hillslopes and channels. In the operational implementation of FloodPROOFS in Aosta Valley, Continuum takes effective-precipitation fields from S3M and inhibits evapotranspiration wherever S3M SWE $>0.01 \mathrm{~mm}$. Like S3M, all parameters for Continuum were set according to well-established operational practices in Aosta Valley. 


\section{Data assimilation}

For assimilating ultrasonic-snow-depth-sensor-based maps as SWE, snow depth is converted to SWE using S3M modeled density; this follows several pieces of evidence showing that spatial variability of, as well as predictive uncertainty for, density is smaller than for snow depth (Mizukami and Perica, 2008; López Moreno et al., 2013). Assimilation is performed using a Newtonian-Relaxation approach, also known as Nudging (Boni et al., 2010). 


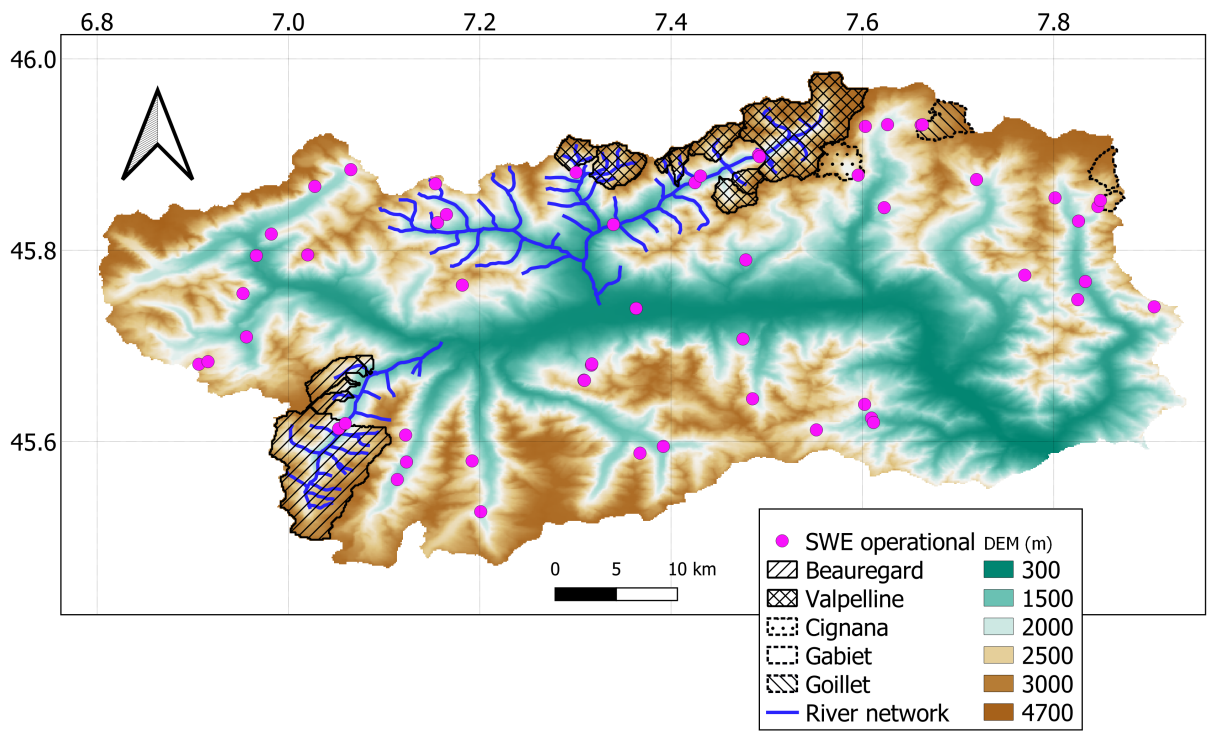

Figure S1. Location of manual, periodical measurements of SWE collected by a cooperative consortium in Aosta Valley and snow-depthsensor measurements for the period 1-8 March 2020. Note that these manual measurements are not classifiable as snow courses, because they consist of stand-alone measurements in flat and open sites. See Figure 1 in the main text for explanation of other elements in this map. 

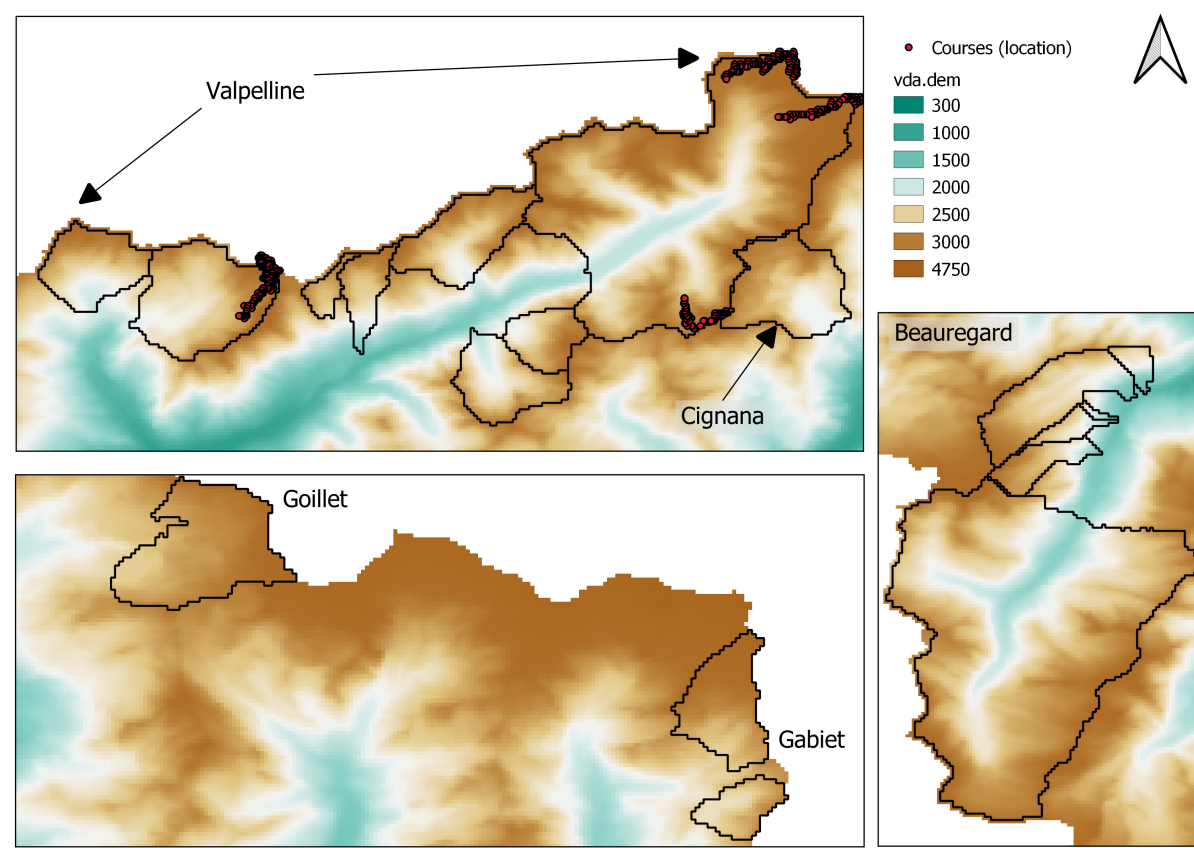

\section{0}

$\square$
$\square \quad 1000$
$\square \quad 1500$

$\square 2000$

2500
$\square \quad 3000$

$\square 750$

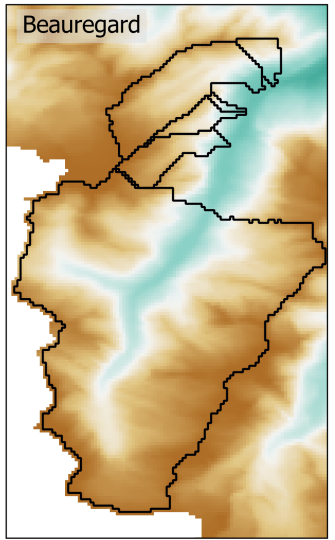

Figure S2. Snow-course locations in Aosta Valley for water year 2008. Table 1 in the main text reports dates of each survey, along with information on elevation covered and number of samples per survey. 

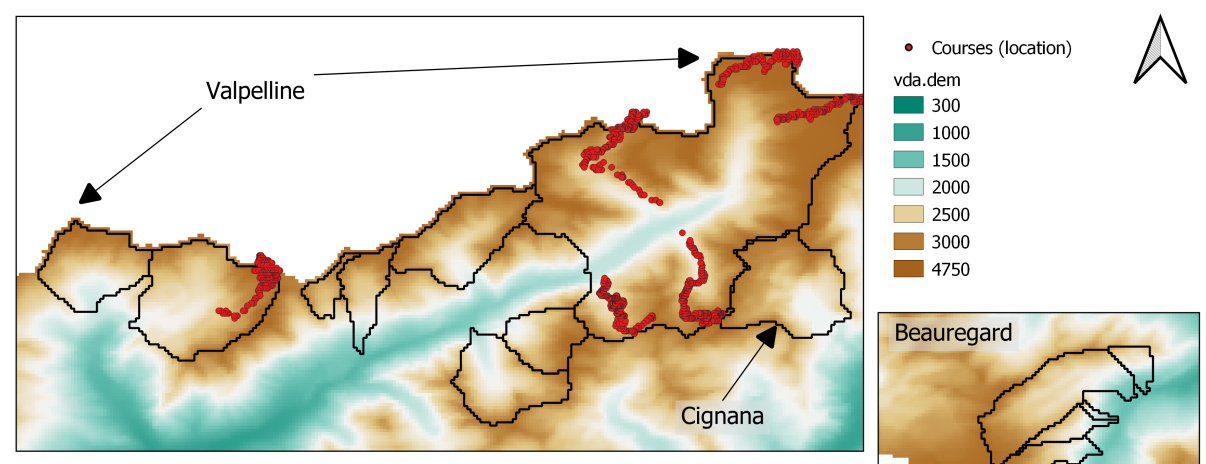

$N$
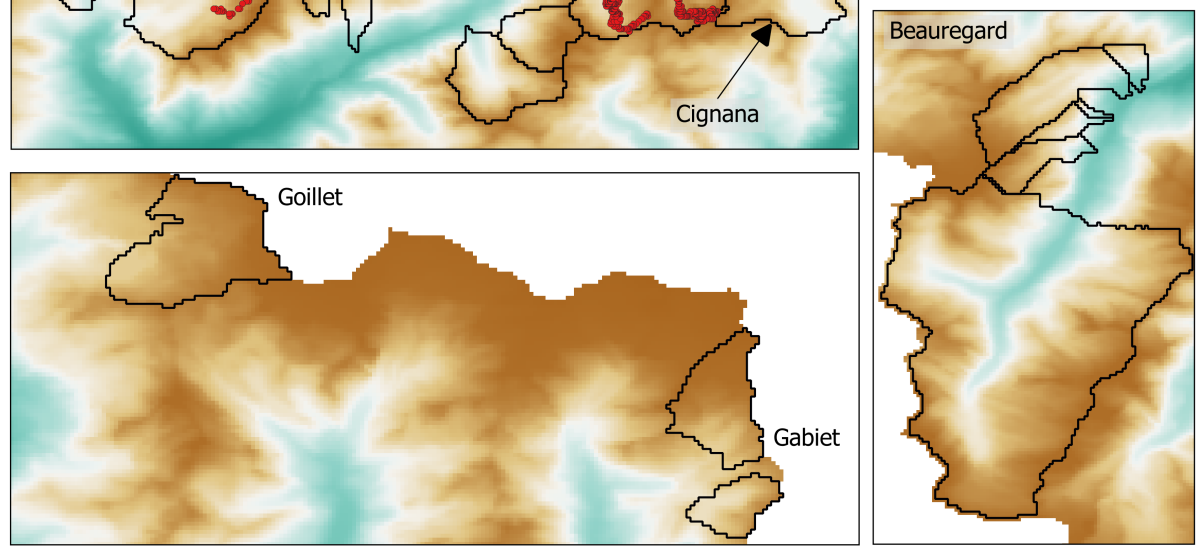

Figure S3. Snow-course locations in Aosta Valley for water year 2009. Table 1 in the main text reports dates of each survey, along with information on elevation covered and number of samples per survey. 

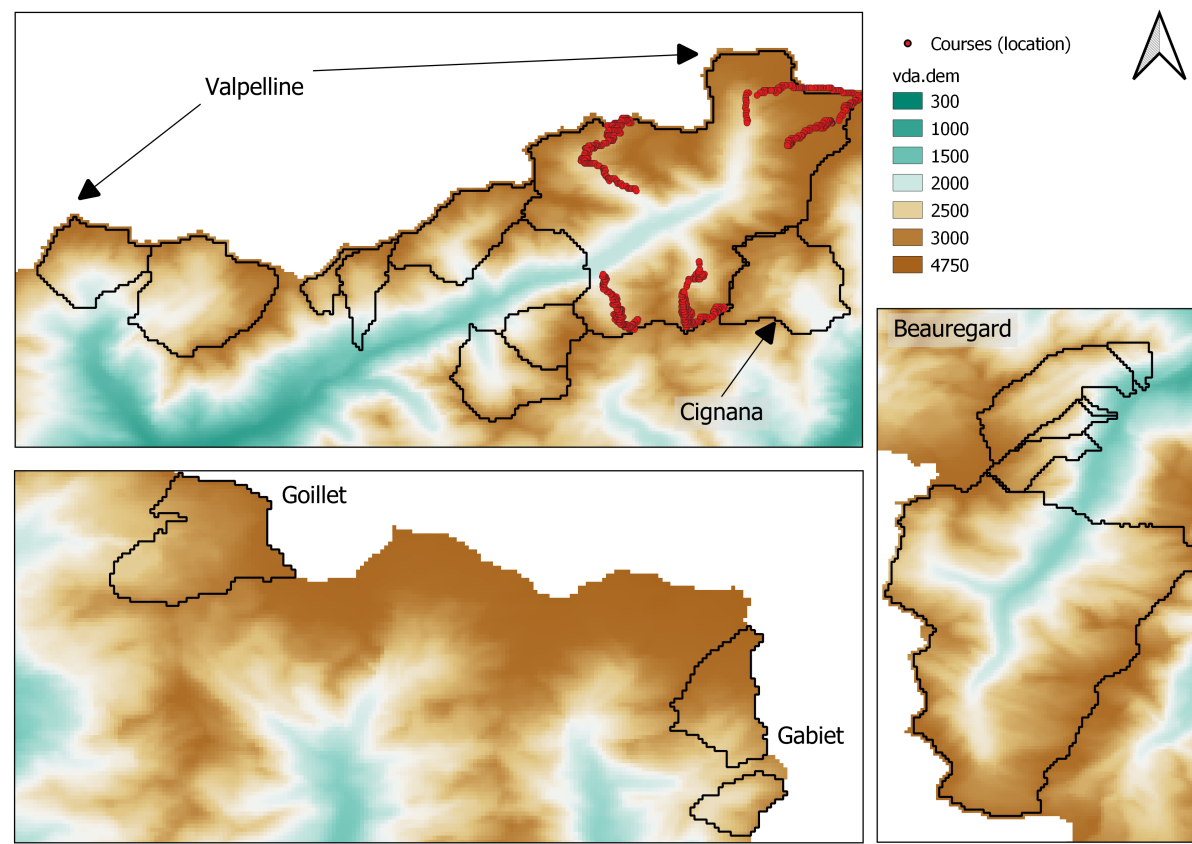

\section{$\begin{array}{r}300 \\ \hline\end{array}$}

$\begin{array}{r}\square \\ \square \\ \square \\ \hline\end{array}$

$\square 2000$

$\square$
$\square$
$\square$
3000

4750

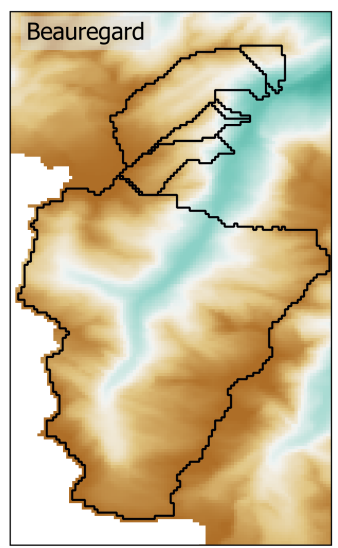

Figure S4. Snow-course locations in Aosta Valley for water year 2010. Table 1 in the main text reports dates of each survey, along with information on elevation covered and number of samples per survey. 

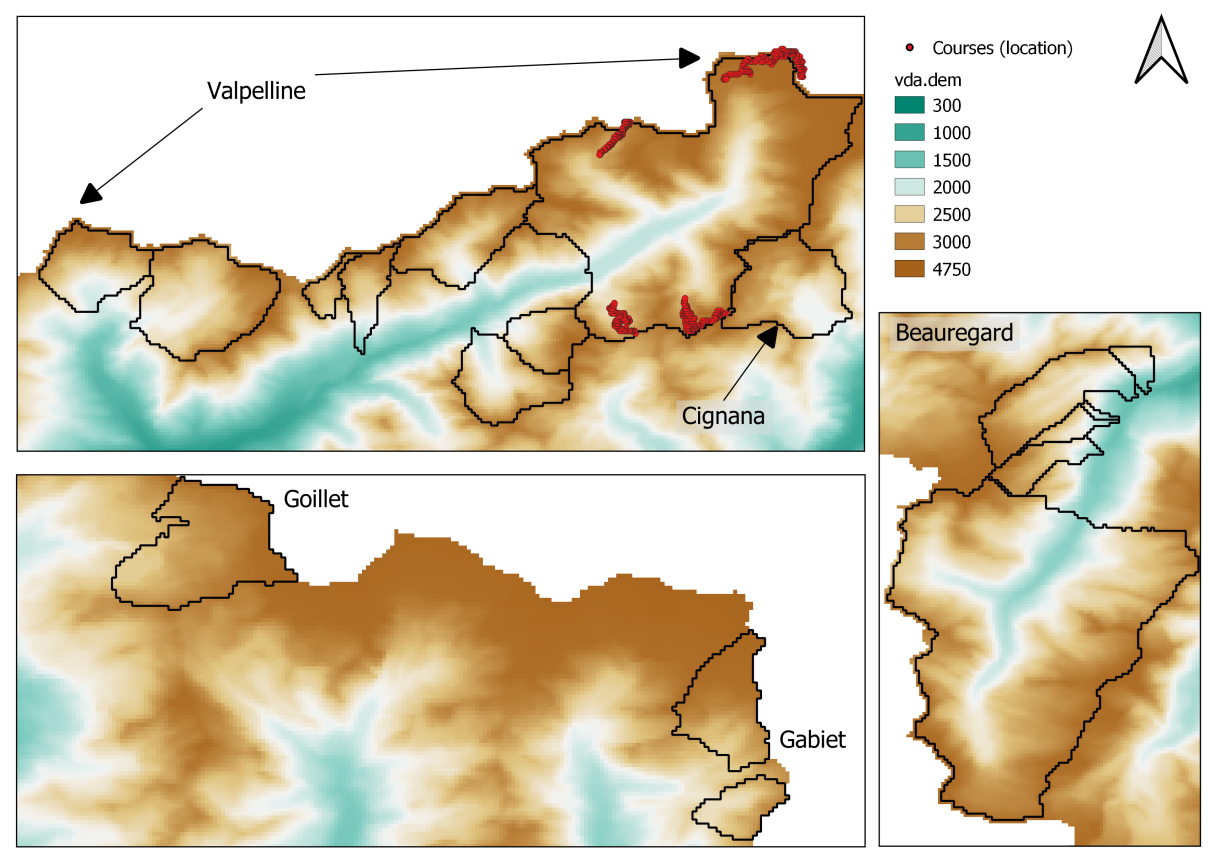

Figure S5. Snow-course locations in Aosta Valley for water year 2011. Table 1 in the main text reports dates of each survey, along with information on elevation covered and number of samples per survey. 

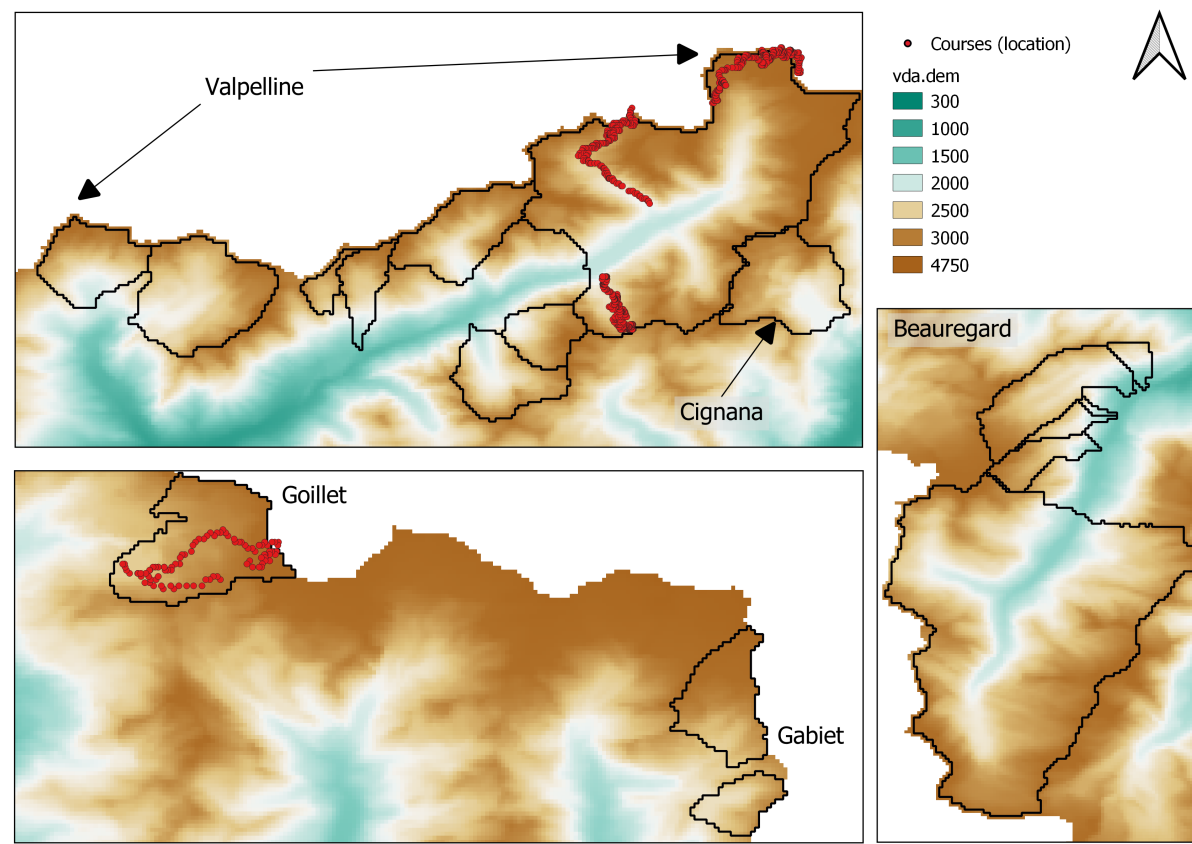

\section{0}

$\square$
$\square \quad 1000$
$\square \quad 1500$

$\square 2000$

$\square$
$\square$
$\square$
3000

4750

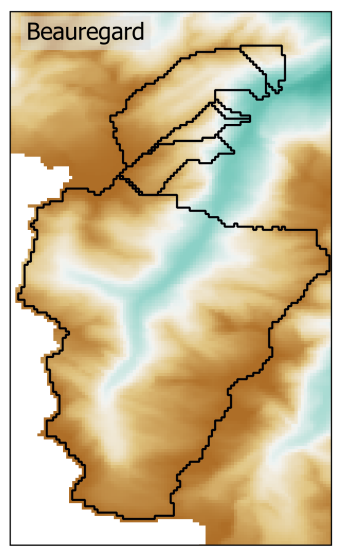

Figure S6. Snow-course locations in Aosta Valley for water year 2012. Table 1 in the main text reports dates of each survey, along with information on elevation covered and number of samples per survey. 

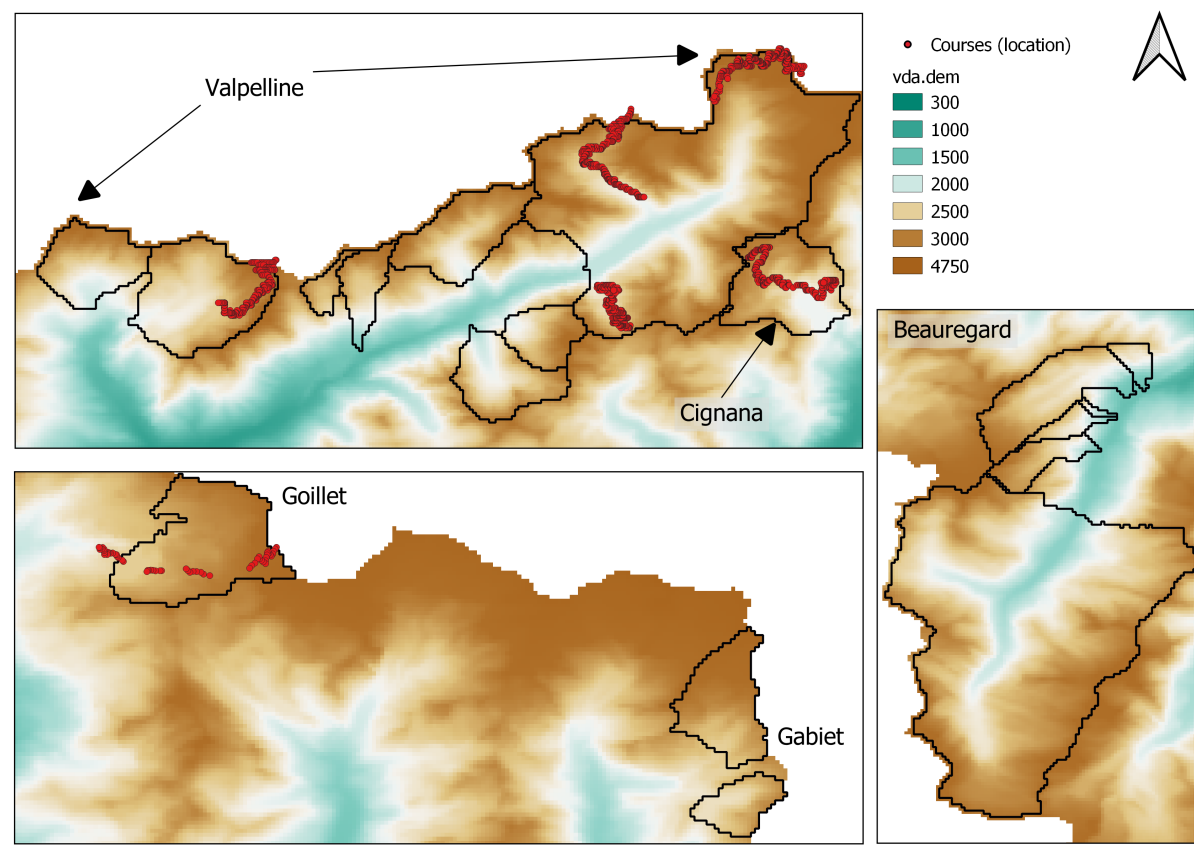

\section{0}

1000
$\square \quad 1500$

$\square 2000$

$\square$
$\square$
$\square$
3000

4750

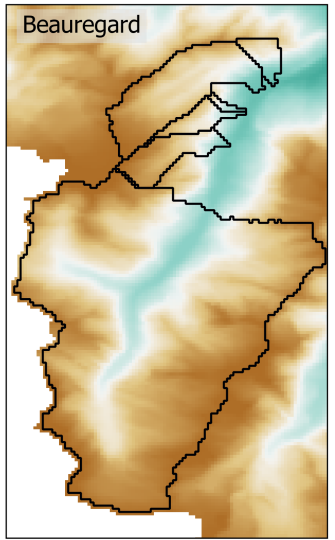

Figure S7. Snow-course locations in Aosta Valley for water year 2013. Table 1 in the main text reports dates of each survey, along with information on elevation covered and number of samples per survey. 

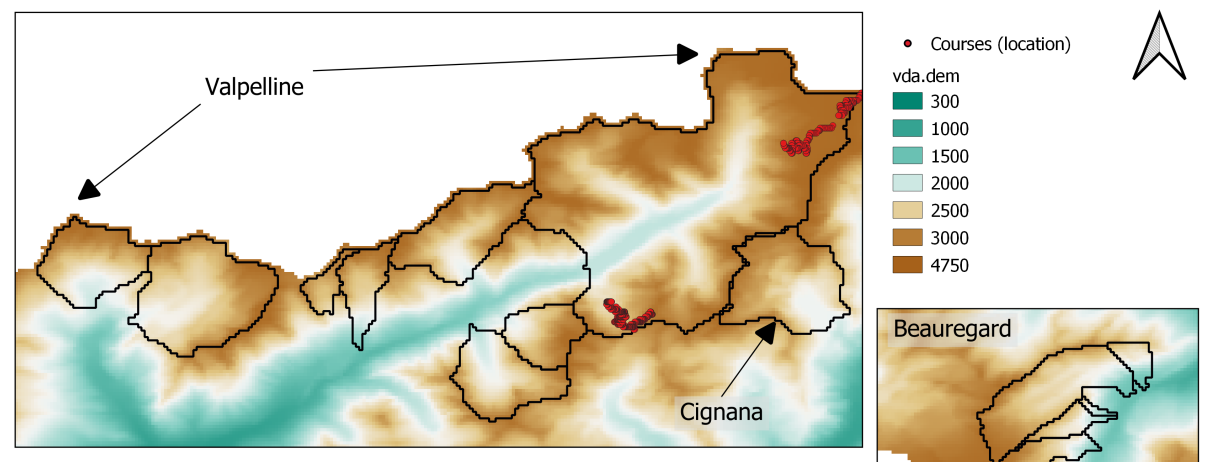

$N$
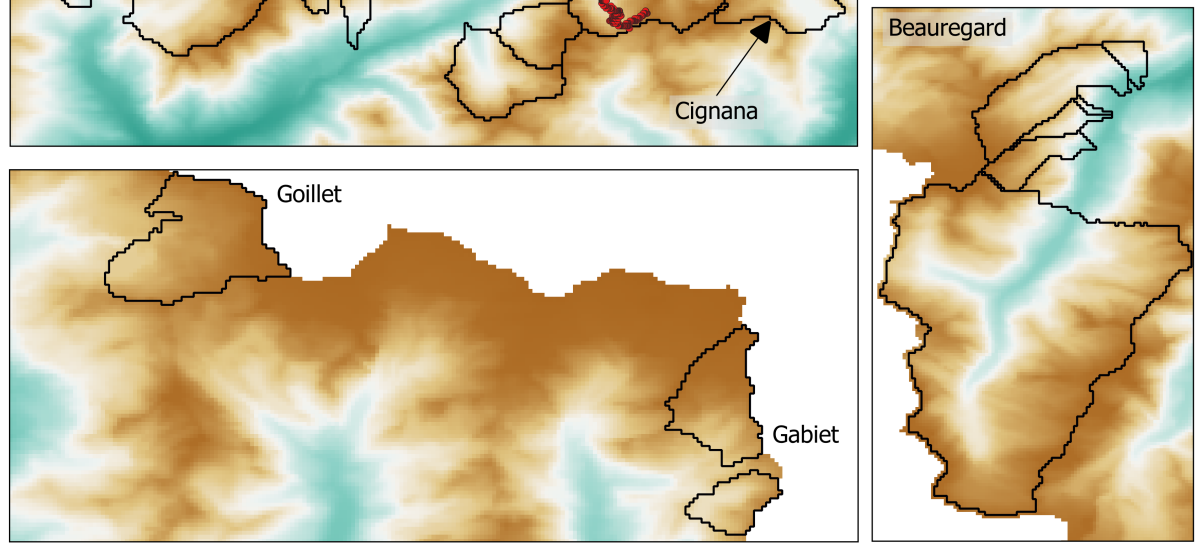

Figure S8. Snow-course locations in Aosta Valley for water year 2015. Table 1 in the main text reports dates of each survey, along with information on elevation covered and number of samples per survey. 

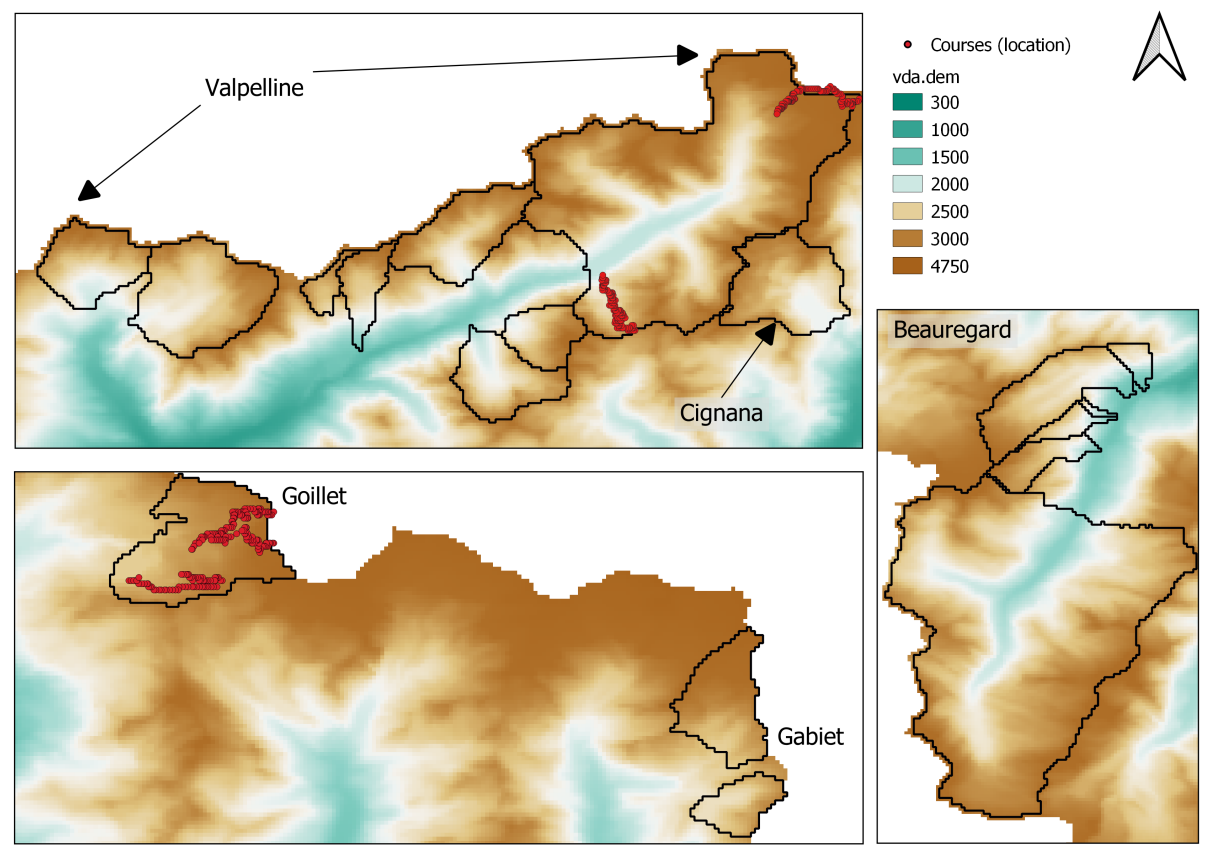

Figure S9. Snow-course locations in Aosta Valley for water year 2016. Table 1 in the main text reports dates of each survey, along with information on elevation covered and number of samples per survey. 

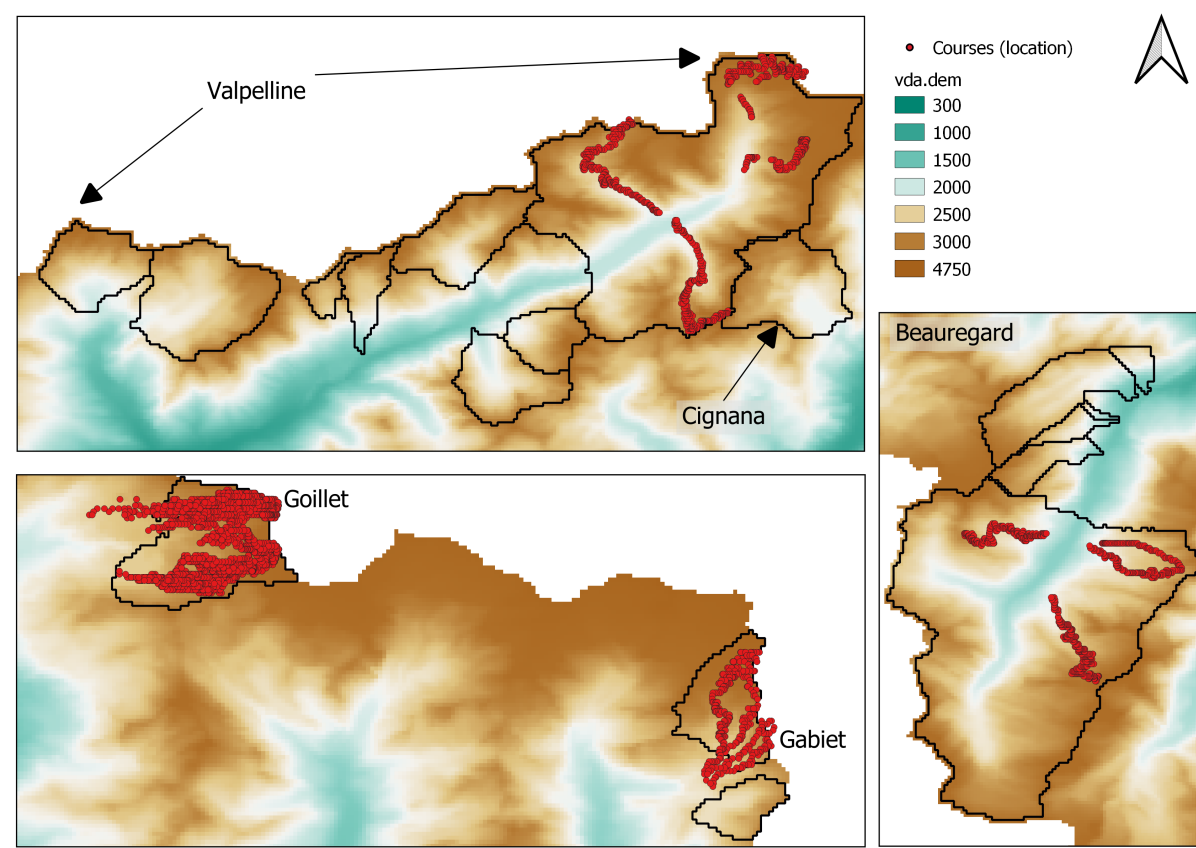

\section{0}

$\square$
$\square$
$\square$
$\square$

$\square 2000$

2500

3000
$\square$
4750

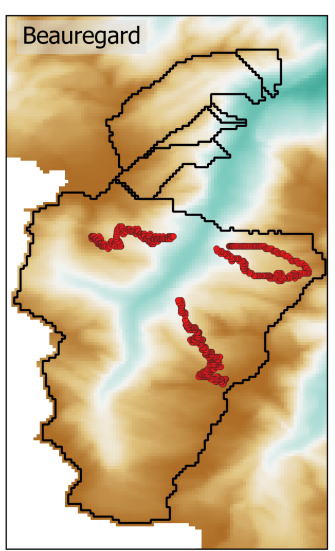

Figure S10. Snow-course locations in Aosta Valley for water year 2017. Table 1 in the main text reports dates of each survey, along with information on elevation covered and number of samples per survey. 

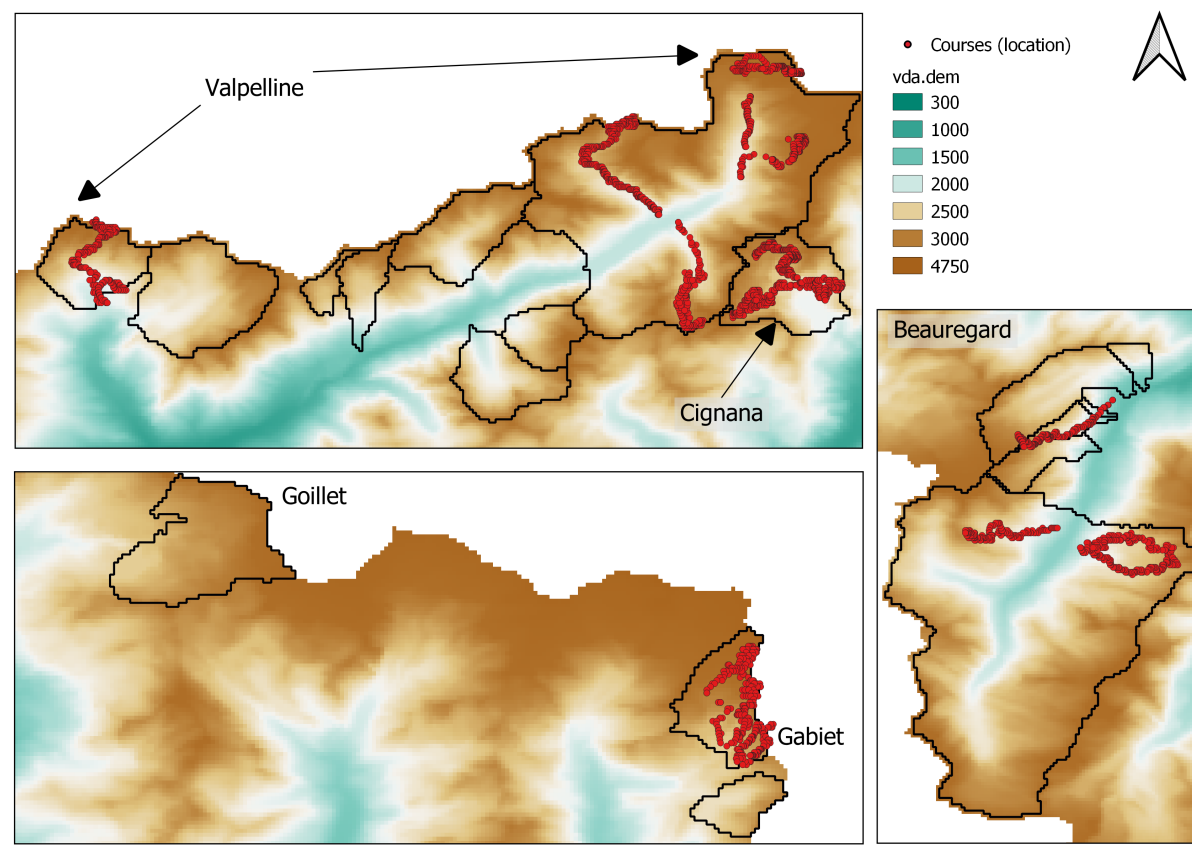

\section{0}

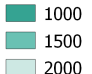

$\square 2000$

- 3000

4750

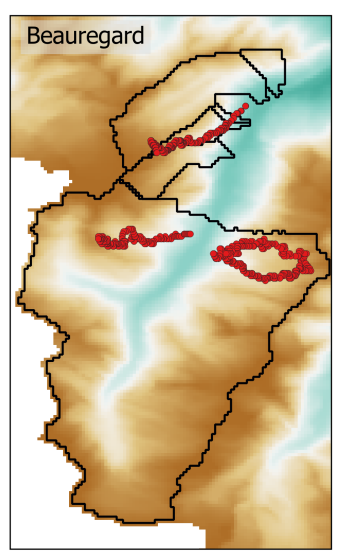

Figure S11. Snow-course locations in Aosta Valley for water year 2018. Table 1 in the main text reports dates of each survey, along with information on elevation covered and number of samples per survey. 

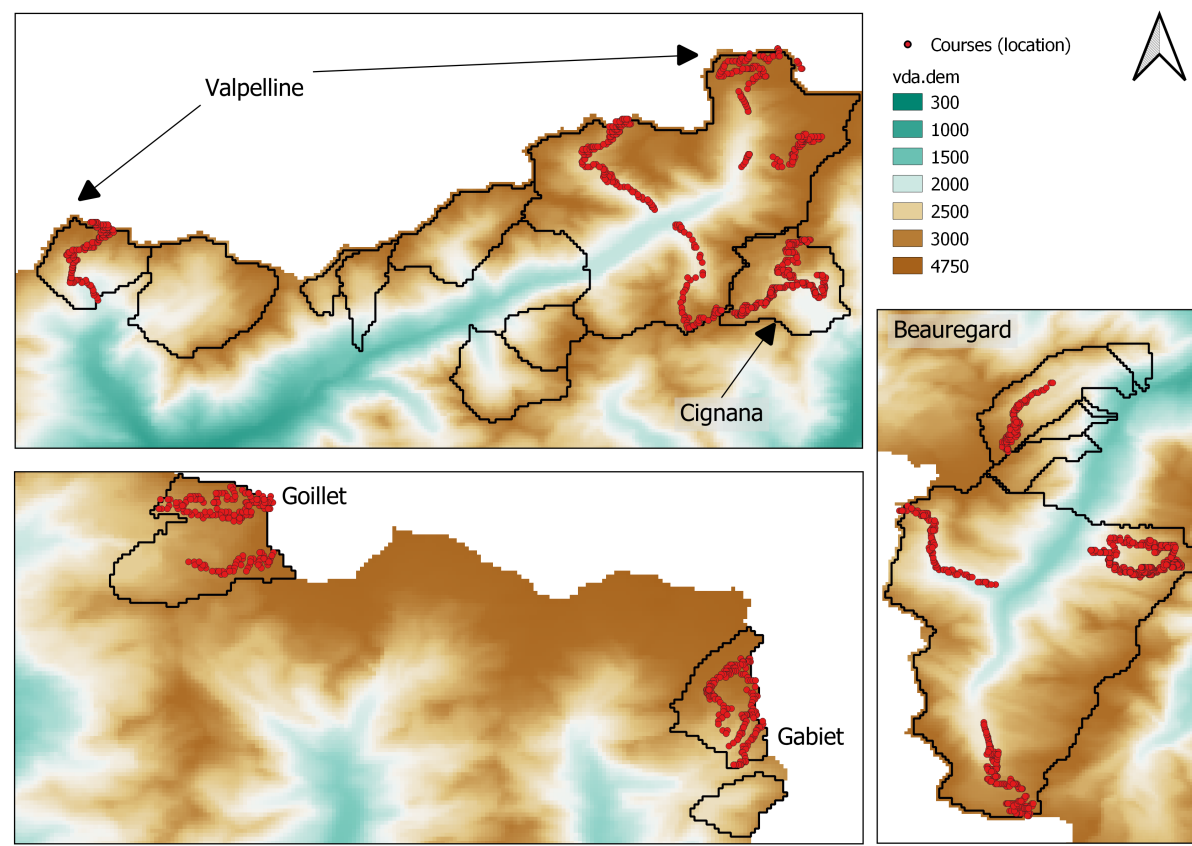

\section{0}

$\begin{array}{r}\square \\ \square \\ \square \\ \hline\end{array}$

$\square 2000$

2500

3000
-4750

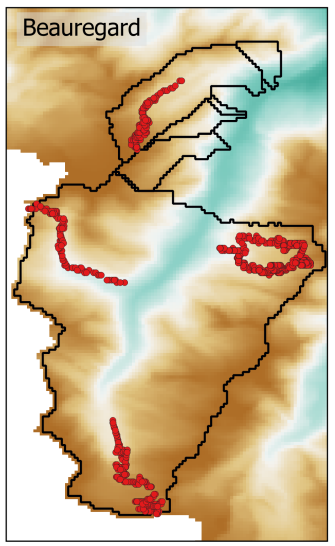

Figure S12. Snow-course locations in Aosta Valley for water year 2019. Table 1 in the main text reports dates of each survey, along with information on elevation covered and number of samples per survey. 


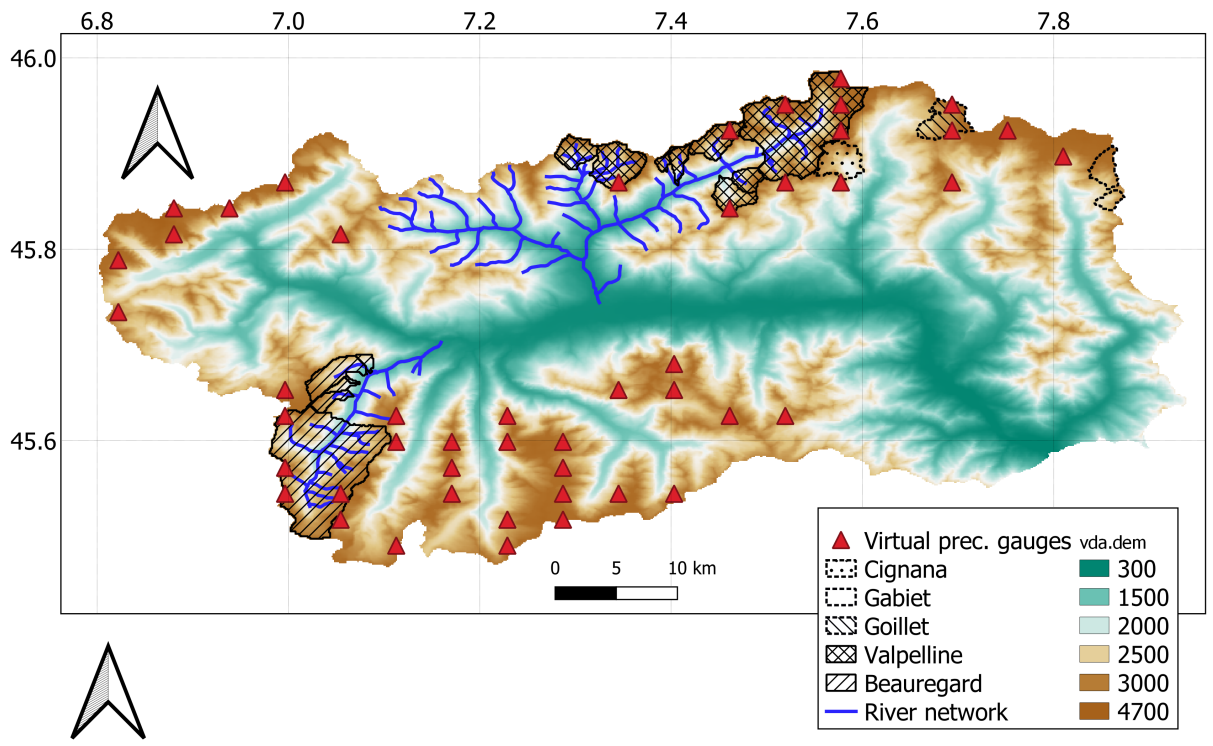

Figure S13. Locations of virtual precipitation gauges in Aosta Valley. Precipitation estimated for these locations through interpolation of physical-precipitation-gauge data was enhanced through blended precipitation lapse rates to account for orographic effects above the precipitation-gauge line. See section 3.2 in the main text for details. 

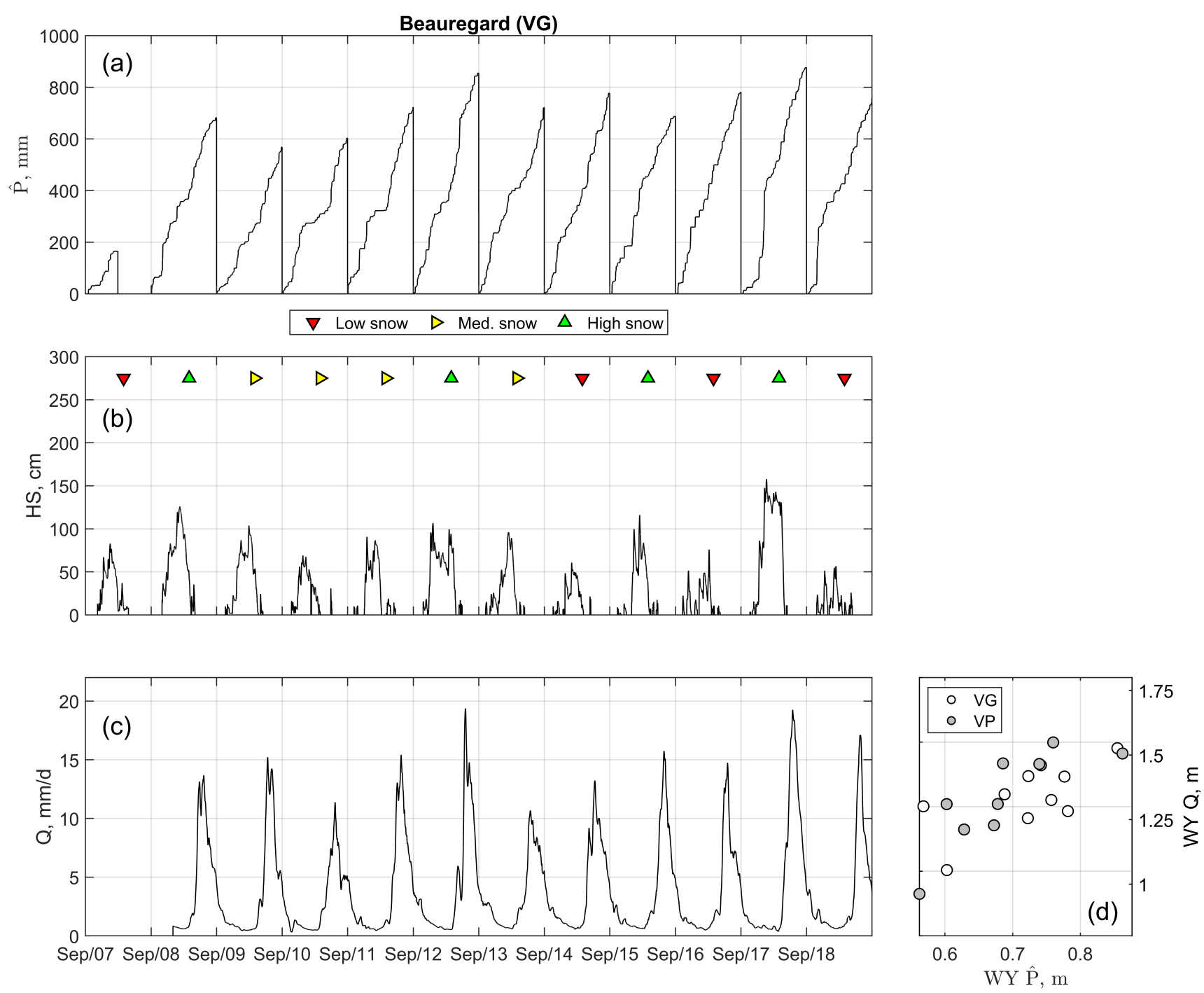

Figure S14. Summary of daily precipitation (a), snow depth (b), and reconstructed streamflow (c) for Beauregard. Precipitation was calculated across all gauges in the valleys of Beauregard (variable $\hat{P}$, see gauge locations in Figure 1, main text). Snow depth was from a representative, mid-elevation sensors (elevation was $\sim 1860 \mathrm{~m} \mathrm{ASL}$ ). Reconstructed streamflow refers to the hydropower catchment delineated in Figure 1, main text. Low, medium, and high snow seasons were estimated based on percentiles of mean seasonal snow depth at Beauregard, which had a complete record between water years 2008 and 2019. This classification is only functional to the scopes of this paper and has no long-term climatological meaning. Panel (d) reports the estimated precipitation-runoff relationship for both hydropower catchments, where WY $\hat{P}$ and WY $Q$ are water-year cumulative precipitation and reconstructed streamflow, respectively ( $\hat{P}$ is systematically smaller than $Q$ because high-elevation headwaters are ungauged). 


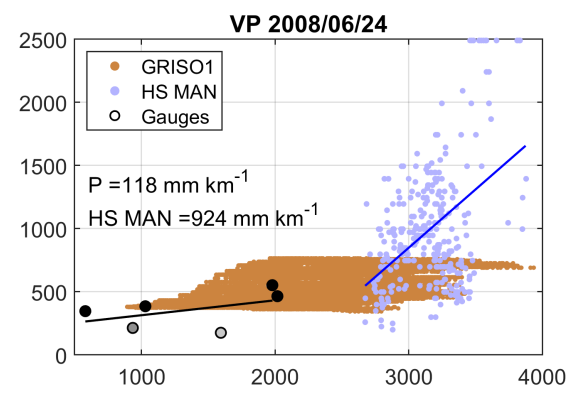



Elevation, $\mathrm{m}$ ASL

Figure S15. Top panels: Winter orographic gradients estimated by precipitation gauges (black dots and line) vs. those estimated by snow courses (blue dots and line) in 2008. The grey scale for precipitation-gauge data points measures the amount of gaps in the time series, with black meaning a complete time series and white a time series with nearly $100 \%$ missing data points. The brown cloud is the winter orographic gradient estimated by GRISO1, which only relied on precipitation gauges. Middle and bottom panels: Orographic gradients estimated by snow courses and precipitation gauges (blue and black lines, respectively) vs. those estimated by the two snow maps that FloodPROOFS assimilated around the snow-course date of 2008 (green is the snow-depth-sensor map, pink is the weekly SWE map). Details on Flood-PROOFS and these assimilated maps are reported in Section 3.3 and S1. VG and VP are Beauregard and Valpelline, respectively. Missing panels imply that some of the information needed to perform this comparison was missing for this water year (e.g., gaps in the snow-depth-sensor record, or frequently no snow-course survey). 


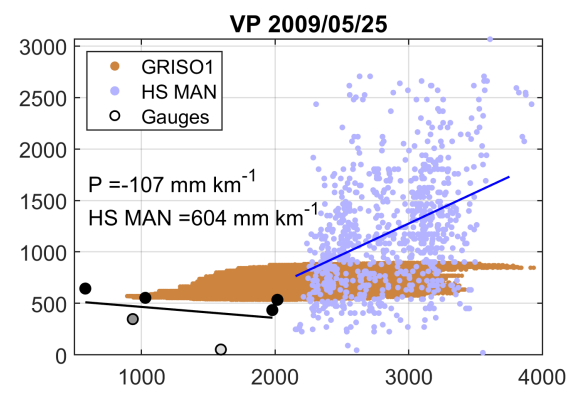



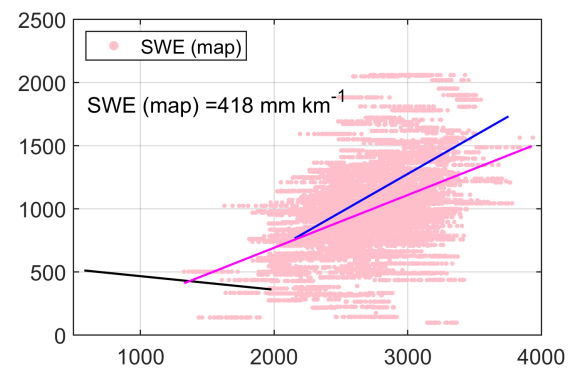

Elevation, $\mathrm{m}$ ASL

Figure S16. Top panels: Winter orographic gradients estimated by precipitation gauges (black dots and line) vs. those estimated by snow courses (blue dots and line) in 2009. The grey scale for precipitation-gauge data points measures the amount of gaps in the time series, with black meaning a complete time series and white a time series with nearly $100 \%$ missing data points. The brown cloud is the winter orographic gradient estimated by GRISO1, which only relied on precipitation gauges. Middle and bottom panels: Orographic gradients estimated by snow courses and precipitation gauges (blue and black lines, respectively) vs. those estimated by the two snow maps that FloodPROOFS assimilated around the snow-course date of 2009 (green is the snow-depth-sensor map, pink is the weekly SWE map). Details on Flood-PROOFS and these assimilated maps are reported in Section 3.3 and S1. VG and VP are Beauregard and Valpelline, respectively. Missing panels imply that some of the information needed to perform this comparison was missing for this water year (e.g., gaps in the snow-depth-sensor record, or frequently no snow-course survey). 


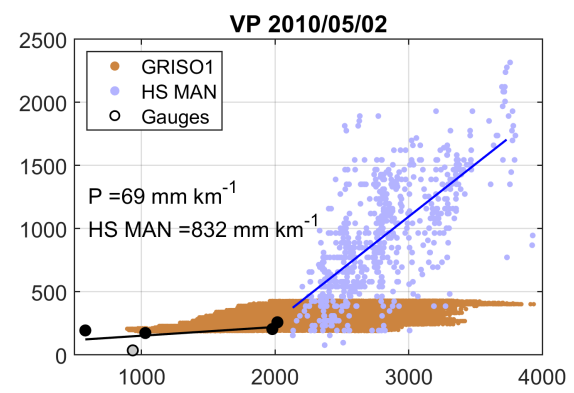



Elevation, $\mathrm{m}$ ASL

Figure S17. Top panels: Winter orographic gradients estimated by precipitation gauges (black dots and line) vs. those estimated by snow courses (blue dots and line) in 2010. The grey scale for precipitation-gauge data points measures the amount of gaps in the time series, with black meaning a complete time series and white a time series with nearly $100 \%$ missing data points. The brown cloud is the winter orographic gradient estimated by GRISO1, which only relied on precipitation gauges. Middle and bottom panels: Orographic gradients estimated by snow courses and precipitation gauges (blue and black lines, respectively) vs. those estimated by the two snow maps that FloodPROOFS assimilated around the snow-course date of 2010 (green is the snow-depth-sensor map, pink is the weekly SWE map). Details on Flood-PROOFS and these assimilated maps are reported in Section 3.3 and S1. VG and VP are Beauregard and Valpelline, respectively. Missing panels imply that some of the information needed to perform this comparison was missing for this water year (e.g., gaps in the snow-depth-sensor record, or frequently no snow-course survey). 


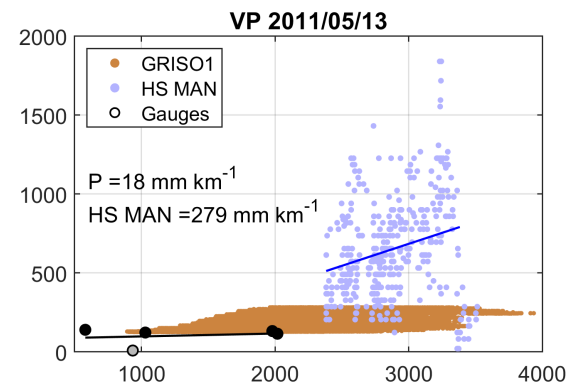

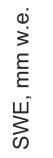

Figure S18. Top panels: Winter orographic gradients estimated by precipitation gauges (black dots and line) vs. those estimated by snow courses (blue dots and line) in 2011. The grey scale for precipitation-gauge data points measures the amount of gaps in the time series, with black meaning a complete time series and white a time series with nearly $100 \%$ missing data points. The brown cloud is the winter orographic gradient estimated by GRISO1, which only relied on precipitation gauges. Middle and bottom panels: Orographic gradients estimated by snow courses and precipitation gauges (blue and black lines, respectively) vs. those estimated by the two snow maps that FloodPROOFS assimilated around the snow-course date of 2011 (green is the snow-depth-sensor map, pink is the weekly SWE map). Details on Flood-PROOFS and these assimilated maps are reported in Section 3.3 and S1. VG and VP are Beauregard and Valpelline, respectively. Missing panels imply that some of the information needed to perform this comparison was missing for this water year (e.g., gaps in the snow-depth-sensor record, or frequently no snow-course survey). 


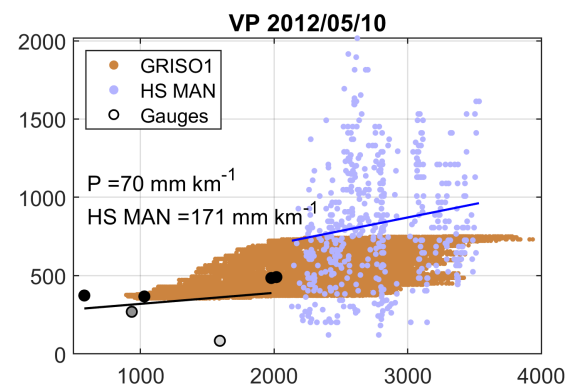

$\stackrel{\infty}{3}$
है
है
कं

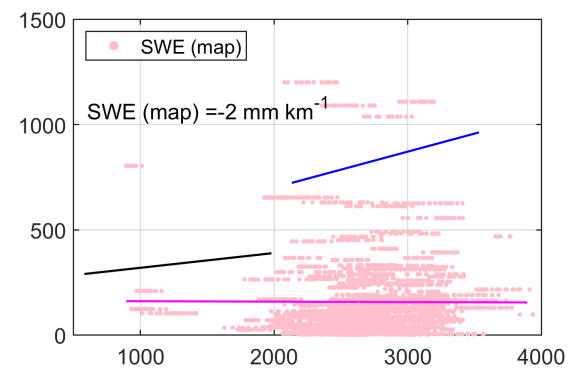

Elevation, m ASL

Figure S19. Top panels: Winter orographic gradients estimated by precipitation gauges (black dots and line) vs. those estimated by snow courses (blue dots and line) in 2012. The grey scale for precipitation-gauge data points measures the amount of gaps in the time series, with black meaning a complete time series and white a time series with nearly $100 \%$ missing data points. The brown cloud is the winter orographic gradient estimated by GRISO1, which only relied on precipitation gauges. Middle and bottom panels: Orographic gradients estimated by snow courses and precipitation gauges (blue and black lines, respectively) vs. those estimated by the two snow maps that FloodPROOFS assimilated around the snow-course date of 2012 (green is the snow-depth-sensor map, pink is the weekly SWE map). Details on Flood-PROOFS and these assimilated maps are reported in Section 3.3 and S1. VG and VP are Beauregard and Valpelline, respectively. Missing panels imply that some of the information needed to perform this comparison was missing for this water year (e.g., gaps in the snow-depth-sensor record, or frequently no snow-course survey). 

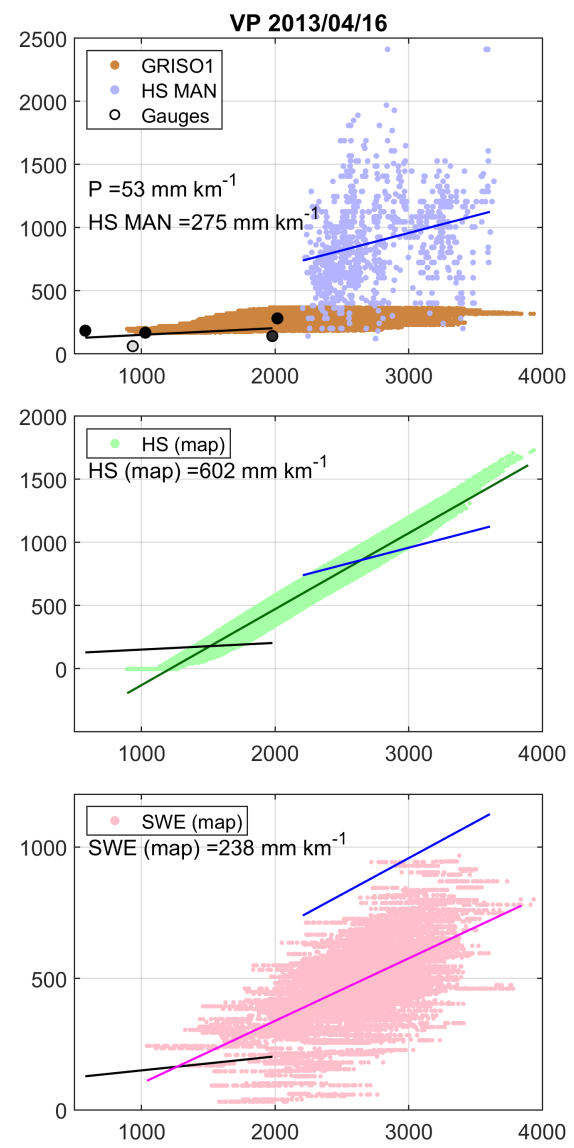

Elevation, m ASL

Figure S20. Top panels: Winter orographic gradients estimated by precipitation gauges (black dots and line) vs. those estimated by snow courses (blue dots and line) in 2013. The grey scale for precipitation-gauge data points measures the amount of gaps in the time series, with black meaning a complete time series and white a time series with nearly $100 \%$ missing data points. The brown cloud is the winter orographic gradient estimated by GRISO1, which only relied on precipitation gauges. Middle and bottom panels: Orographic gradients estimated by snow courses and precipitation gauges (blue and black lines, respectively) vs. those estimated by the two snow maps that FloodPROOFS assimilated around the snow-course date of 2013 (green is the snow-depth-sensor map, pink is the weekly SWE map). Details on Flood-PROOFS and these assimilated maps are reported in Section 3.3 and S1. VG and VP are Beauregard and Valpelline, respectively. Missing panels imply that some of the information needed to perform this comparison was missing for this water year (e.g., gaps in the snow-depth-sensor record, or frequently no snow-course survey). 


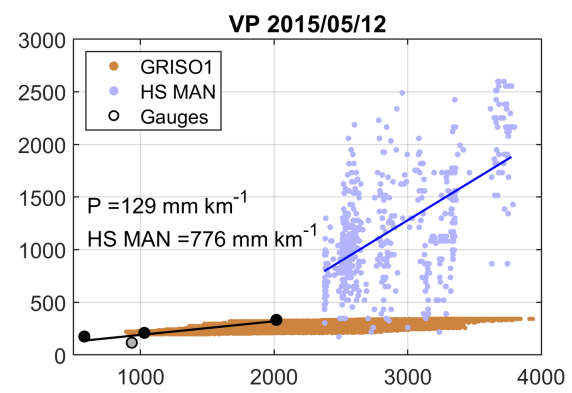



Elevation, $\mathrm{m}$ ASL

Figure S21. Top panels: Winter orographic gradients estimated by precipitation gauges (black dots and line) vs. those estimated by snow courses (blue dots and line) in 2015. The grey scale for precipitation-gauge data points measures the amount of gaps in the time series, with black meaning a complete time series and white a time series with nearly $100 \%$ missing data points. The brown cloud is the winter orographic gradient estimated by GRISO1, which only relied on precipitation gauges. Middle and bottom panels: Orographic gradients estimated by snow courses and precipitation gauges (blue and black lines, respectively) vs. those estimated by the two snow maps that FloodPROOFS assimilated around the snow-course date of 2015 (green is the snow-depth-sensor map, pink is the weekly SWE map). Details on Flood-PROOFS and these assimilated maps are reported in Section 3.3 and S1. VG and VP are Beauregard and Valpelline, respectively. Missing panels imply that some of the information needed to perform this comparison was missing for this water year (e.g., gaps in the snow-depth-sensor record, or frequently no snow-course survey). 

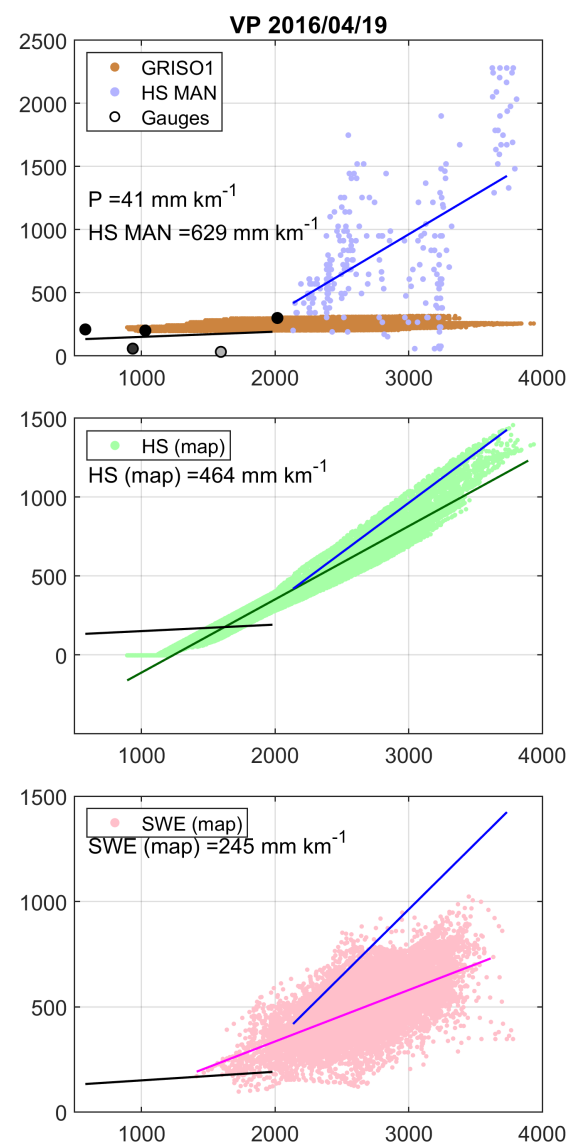

Elevation, m ASL

Figure S22. Top panels: Winter orographic gradients estimated by precipitation gauges (black dots and line) vs. those estimated by snow courses (blue dots and line) in 2016. The grey scale for precipitation-gauge data points measures the amount of gaps in the time series, with black meaning a complete time series and white a time series with nearly $100 \%$ missing data points. The brown cloud is the winter orographic gradient estimated by GRISO1, which only relied on precipitation gauges. Middle and bottom panels: Orographic gradients estimated by snow courses and precipitation gauges (blue and black lines, respectively) vs. those estimated by the two snow maps that FloodPROOFS assimilated around the snow-course date of 2016 (green is the snow-depth-sensor map, pink is the weekly SWE map). Details on Flood-PROOFS and these assimilated maps are reported in Section 3.3 and S1. VG and VP are Beauregard and Valpelline, respectively. Missing panels imply that some of the information needed to perform this comparison was missing for this water year (e.g., gaps in the snow-depth-sensor record, or frequently no snow-course survey). 

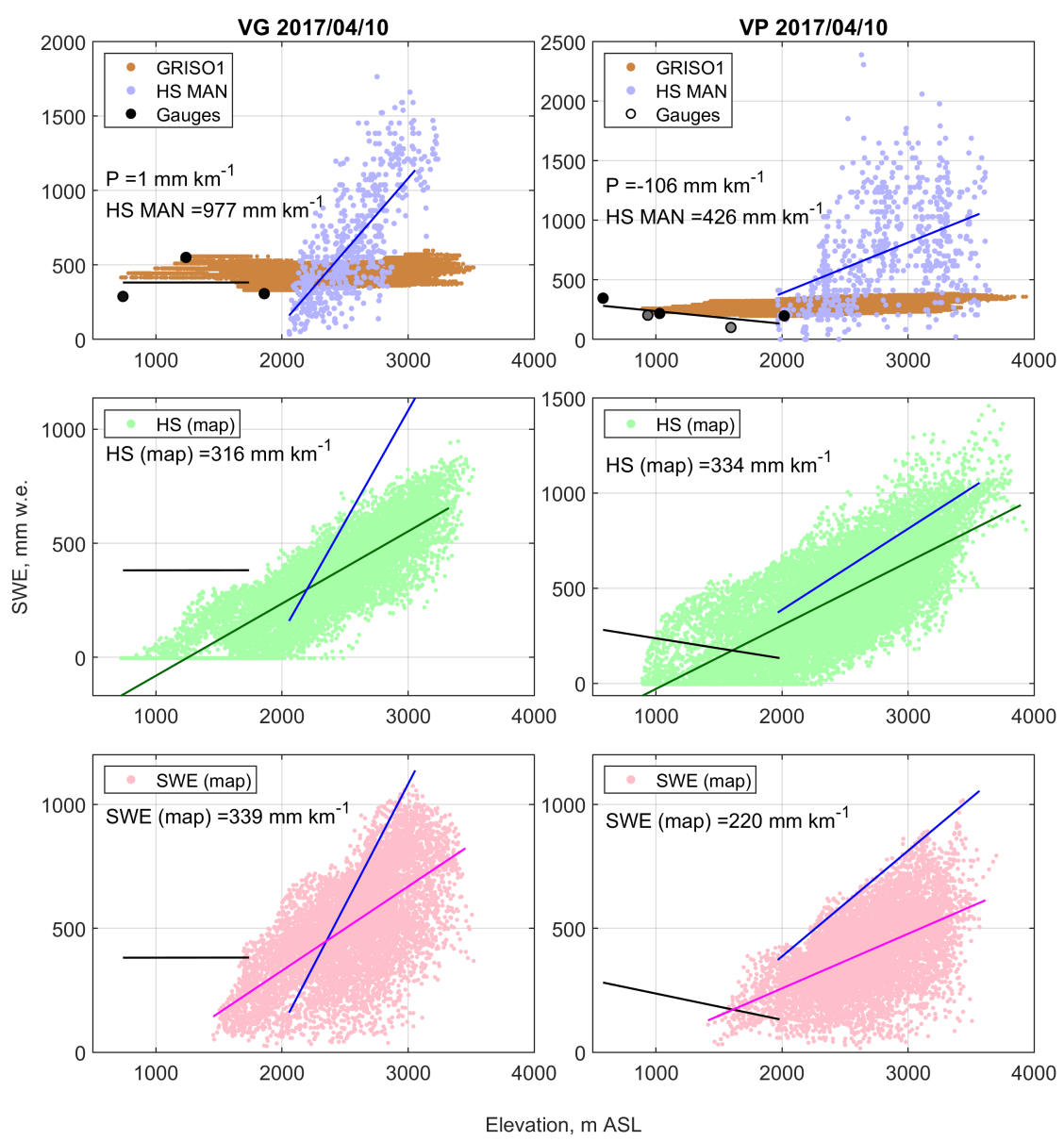

Figure S23. Top panels: Winter orographic gradients estimated by precipitation gauges (black dots and line) vs. those estimated by snow courses (blue dots and line) in 2017. The grey scale for precipitation-gauge data points measures the amount of gaps in the time series, with black meaning a complete time series and white a time series with nearly $100 \%$ missing data points. The brown cloud is the winter orographic gradient estimated by GRISO1, which only relied on precipitation gauges. Middle and bottom panels: Orographic gradients estimated by snow courses and precipitation gauges (blue and black lines, respectively) vs. those estimated by the two snow maps that FloodPROOFS assimilated around the snow-course date of 2017 (green is the snow-depth-sensor map, pink is the weekly SWE map). Details on Flood-PROOFS and these assimilated maps are reported in Section 3.3 and S1. VG and VP are Beauregard and Valpelline, respectively. Missing panels imply that some of the information needed to perform this comparison was missing for this water year (e.g., gaps in the snow-depth-sensor record, or frequently no snow-course survey). 

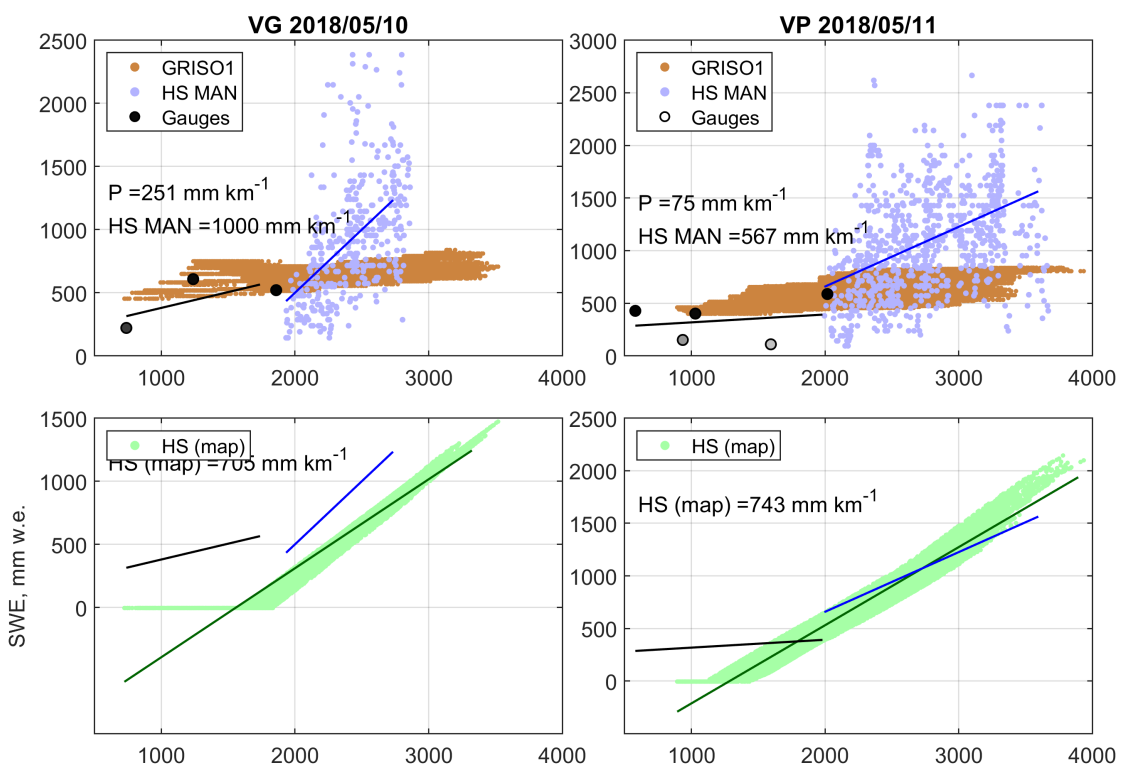

Elevation, $\mathrm{m}$ ASL

Figure S24. Top panels: Winter orographic gradients estimated by precipitation gauges (black dots and line) vs. those estimated by snow courses (blue dots and line) in 2018. The grey scale for precipitation-gauge data points measures the amount of gaps in the time series, with black meaning a complete time series and white a time series with nearly $100 \%$ missing data points. The brown cloud is the winter orographic gradient estimated by GRISO1, which only relied on precipitation gauges. Middle and bottom panels: Orographic gradients estimated by snow courses and precipitation gauges (blue and black lines, respectively) vs. those estimated by the two snow maps that FloodPROOFS assimilated around the snow-course date of 2018 (green is the snow-depth-sensor map, pink is the weekly SWE map). Details on Flood-PROOFS and these assimilated maps are reported in Section 3.3 and S1. VG and VP are Beauregard and Valpelline, respectively. Missing panels imply that some of the information needed to perform this comparison was missing for this water year (e.g., gaps in the snow-depth-sensor record, or frequently no snow-course survey). 

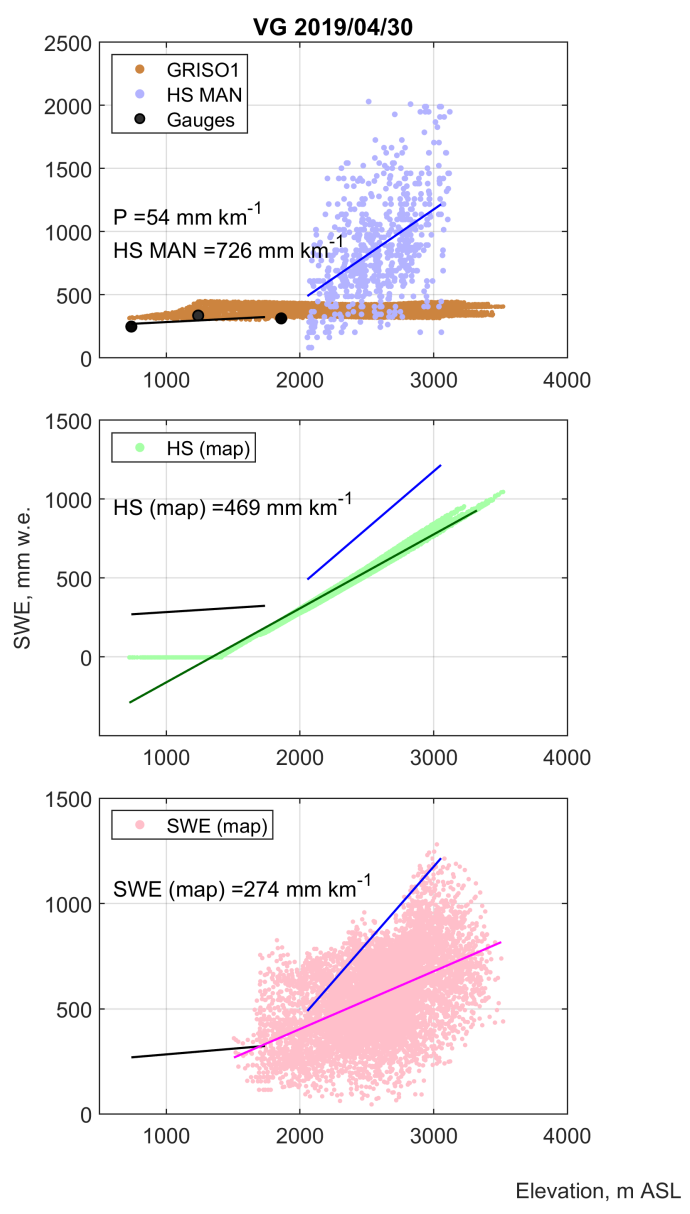

Figure S25. Top panels: Winter orographic gradients estimated by precipitation gauges (black dots and line) vs. those estimated by snow courses (blue dots and line) in 2019. The grey scale for precipitation-gauge data points measures the amount of gaps in the time series, with black meaning a complete time series and white a time series with nearly $100 \%$ missing data points. The brown cloud is the winter orographic gradient estimated by GRISO1, which only relied on precipitation gauges. Middle and bottom panels: Orographic gradients estimated by snow courses and precipitation gauges (blue and black lines, respectively) vs. those estimated by the two snow maps that FloodPROOFS assimilated around the snow-course date of 2019 (green is the snow-depth-sensor map, pink is the weekly SWE map). Details on Flood-PROOFS and these assimilated maps are reported in Section 3.3 and S1. VG and VP are Beauregard and Valpelline, respectively. Missing panels imply that some of the information needed to perform this comparison was missing for this water year (e.g., gaps in the snow-depth-sensor record, or frequently no snow-course survey). 


\section{References}

Boni, G., Castelli, F., Gabellani, S., Machiavello, G., and Rudari, R.: Assimilation of MODIS snow cover and real time snow depth point data in a snow dynamic model, in: 2010 IEEE International Geoscience and Remote Sensing Symposium, pp. 1788-1791, 2010.

DeWalle, D. R. and Rango, A.: Principles of Snow Hydrology, Cambridge University Press, 2011.

Froidurot, S., Zin, I., Hingray, B., and Gautheron, A.: Sensitivity of Precipitation Phase over the Swiss Alps to Different Meteorological Variables, Journal of Hydrometeorology, 15, 685-696, https://doi.org/10.1175/JHM-D-13-073.1, 2014.

45 Laiolo, P., Gabellani, S., Rebora, N., Rudari, R., Ferraris, L., Ratto, S., Stevenin, H., and Cauduro, M.: Validation of the Flood-PROOFS probabilistic forecasting system, Hydrological Processes, 28, 3466-3481, https://doi.org/10.1002/hyp.9888, 2014.

Laramie, R. L. and Schaake, J. C. J.: Simulation of the continuous snowmelt process, Tech. rep., MIT, Cambridge, 1972.

López Moreno, J. I., Fassnacht, S. R., Heath, J. T., Musselman, K. N., Revuelto, J., Latron, J., Móran-Tejeda, E., and Jonas, T.: Small scale spatial variability of snow density and depth over complex alpine terrain: Implications for estimating snow water equivalent, Advances in Water Resources, 55, 40-52, 2013.

Mizukami, N. and Perica, S.: Spatiotemporal Characteristics of Snowpack Density in the Mountainous Regions of the Western United States, Journal of Hydrometeorology, 9, 1416-1426, https://doi.org/http://dx.doi.org/10.1175/2008JHM981.1, 2008.

Pomeroy, J. and Brun, E.: Physical properties of snow, Snow ecology: An interdisciplinary examination of snow-covered ecosystems, pp. 45-126, 2001.

55 Silvestro, F., Gabellani, S., Delogu, F., Rudari, R., and Boni, G.: Exploiting remote sensing land surface temperature in distributed hydrological modelling: the example of the Continuum model, Hydrology and Earth System Sciences, 17, 39-62, https://doi.org/10.5194/hess-1739-2013, https://www.hydrol-earth-syst-sci.net/17/39/2013/, 2013.

Terzago, S., Andreoli, V., Arduini, G., Balsamo, G., Campo, L., Cassardo, C., Cremonese, E., Dolia, D., Gabellani, S., von Hardenberg, J., Morra di Cella, U., Palazzi, E., Piazzi, G., Pogliotti, P., and Provenzale, A.: Sensitivity of snow models to the accuracy of meteorological forcings in mountain environment, Hydrology and Earth System Sciences Discussions, 2019, 1-32, https://doi.org/10.5194/hess-2019511, https://www.hydrol-earth-syst-sci-discuss.net/hess-2019-511/, 2019. 